\title{
POTENCIALIDADE DE UTILIZAÇÃO DO COPRODUTO DA EXTRAÇÃO DE AZEITE DE OLIVA EXTRAVIRGEM (TORTA DE OLIVA) NA NUTRIÇÃO DE RUMINANTES
}

\author{
OLIVEIRA, J.L.01; RIZZO, F.A.2; SCHEIBLER, R.B.2; SCHAFHÄUSER J.R., J.3; NÖRNBERG, J.L.4; VARGAS, D.P5.
}

PALAVRAS-CHAVE: Alimentação animal. Azeite de oliva. Inoculante. Ruminantes. Silagem.

\begin{abstract}
RESUMO
A obtenção do azeite de oliva está associada com grande quantidade de coproduto (torta de oliva). Assim, objetivou-se avaliar a preservação das características bromatológicas originais da torta de oliva em dois tempos de estocagem ( 0 e 48 horas), além do efeito da adição de inoculante comercial e farelo de trigo (torta de oliva sem inoculante; torta de oliva com inoculante; torta de oliva com inoculante e 15\% de farelo de trigo; e torta de oliva com inoculante e $30 \%$ de farelo de trigo) no pH da silagem deste coproduto. Na torta de oliva foram determinados os teores de matéria seca (MS), matéria orgânica (MO), matéria mineral (MM), extrato etéreo (EE), fibra insolúvel em detergente neutro corrigida para cinzas (FDNc), fibra insolúvel em detergente ácido corrigida para cinzas (FDAc), lignina em detergente ácido (LDA), proteína bruta (PB), nitrogênio insolúvel em detergente neutro (NIDN), nitrogênio insolúvel em detergente ácido (NIDA), digestibilidade verdadeira da MS (DIVMS30 e DIVMS48), digestibilidade verdadeira da FDN (DIVFDN30 e DIVFDN48), nutrientes digestíveis totais (NDT Weiss), carboidratos não fibrosos (CNF) e carboidratos solúveis (CHOS). A composição bromatológica e digestibilidade da torta de oliva não diferiu $(P>0,05)$ nos tempos de estocagem, exceto quanto ao teor de $\mathrm{CHOS}$, que diminuiu $(P<0,05)$ com 48 horas de armazenamento. Além disso, obteve-se os menores $(P<0,05)$ valores de $\mathrm{pH}$ na silagem de torta de oliva com inoculante e $30 \%$ de farelo de trigo. Os resultados deste estudo demonstram que este coproduto pode representar alternativa alimentar para o aumento da densidade energética na nutrição de ruminantes.
\end{abstract}

\section{POTENTIALITY IN THE USE OF CO-PRODUCT OF VIRGIN OLIVE OIL EXTRACTION (OLIVE POMACE) IN THE NUTRITION OF RUMINANTS}

KEYWORDS: Animal feed. Olive oil. Inoculant. Ruminants. Silage.

\begin{abstract}
Obtaining olive oil is associated with a large amount of co-product (olive pomace). Thus, the objective was to evaluate the preservation of the original bromatological characteristics of the olive pomace in two storage times ( 0 and 48 hours) and to the effect of the addition of commercial inoculant and wheat bran (olive pomace without inoculant; olive pomace with inoculant; olive pomace with inoculant and $15 \%$ wheat bran; and olive pomace with inoculant and $30 \%$ wheat bran) at the $\mathrm{pH}$ of the silage of this co-product. The contents of dry matter (DM), organic matter (OM), mineral matter (MM), ether extract (EE), insoluble fiber in neutral detergent corrected for ash (NDFa), insoluble fiber in acid detergent corrected for ash (ADFa), acid detergent lignin (ADL), crude protein (CP), neutral detergent insoluble nitrogen (NDIN), acid detergent insoluble nitrogen (ADIN), true DM digestibility (TDMD30 and TDMD48), true NDF digestibility (TNDFD30 and TNDFD48), total digestible nutrients (TDN Weiss), non-fibrous carbohydrates (NFC) and soluble carbohydrates (SCHO). The bromatological composition and digestibility of the olive pomace did not differ $(P>0.05)$ in storage times, except for the content of SCHO, which decreased $(P<0.05)$ with 48 hours of storage. In addition, the lowest $(P<0.05) \mathrm{pH}$ values were obtained in the silage of olive pomace with inoculant and $30 \%$ of wheat bran. The results of this study demonstrate that this co-product can represent a food alternative for increasing energy density in ruminant nutrition.
\end{abstract}

\footnotetext{
${ }^{1}$ Acadêmico do curso de Medicina Veterinária da Universidade de Santa Cruz do Sul, Santa Cruz do Sul, RS.

2 Programa de Pós-graduação em Zootecnia, Universidade Federal de Pelotas, Pelotas, RS.

${ }^{3}$ Empresa Brasileira de Pesquisa Agropecuária, Embrapa Clima Temperado, Pelotas, RS.

${ }^{4}$ Docente do Programa de Pós-graduação em Ciência e Tecnologia dos Alimentos (PPGCTA), Universidade Federal de Santa, Santa Maria, RS.

${ }^{5}$ Autor para correspondência: Docente do Programa de Pós-Graduação em Tecnologia Ambiental (PPGTA), Universidade de Santa Cruz do Sul, Santa Cruz do Sul, RS<diegoprado@unisc.br>.
} 


\section{INTRODUÇÃO}

Segundo dados do International Olive Council (2021), o Brasil é o terceiro maior importador de azeite de oliva. 0 país contém regiões com condições edafoclimáticas adequadas para o cultivo de oliveiras e por isso, a olivicultura vem despertando interesse nos últimos anos, sendo que em termos de produção comercial ainda é uma atividade agrícola emergente, porém em expansão (COUTINHO et al., 2009).

0 processamento de azeitonas para obtenção de azeite de oliva extravirgem, obtido a frio, tanto por prensagem e decantação ou por sistema contínuo seguido de centrifugação, apresenta baixo rendimento, resultando em coproduto (torta de oliva) constituído por polpa, caroço (noz), pele e água (WEINBERG et al., 2008).

Assim, a obtenção do azeite de oliva extravirgem está associada com a produção de grandes quantidades de torta de oliva, que é de difícil eliminação, podendo gerar passivo ambiental, caso não tenha a correta destinação (VARGAS-BELO-PÉREZ et al., 2013). A extração a frio tem o objetivo de preservar a qualidade do azeite de oliva, o que promove uma extração parcial, tornando este resíduo industrial uma alternativa de fonte lipídica para a nutrição de ruminantes.

Atualmente, a cadeia produtiva das oliveiras não explora a utilização da torta de oliva para a alimentação de ruminantes, em razão da escassez de informações a respeito de suas características químicas e sobre as formas de sua conservação, já que pelo seu elevado teor lipídico, está sujeito a oxidação, o que poderia dificultar a logística de transporte e o manejo deste coproduto à nível de propriedade rural.

Assim, objetivou-se caracterizar bromatologicamente a torta de oliva em diferentes períodos após sua obtenção na indústria (0 e 48 horas), com a finalidade de avaliar a preservação das suas características originais até 48 horas de estocagem, e sua consequente viabilidade para a ensilagem, além do efeito da adição de inoculante comercial e farelo de trigo no decréscimo do pH da silagem deste coproduto.

\section{MATERIAIS E MÉTODOS}

O resíduo da extração do azeite de oliva extravirgem (torta de oliva) foi obtido a partir da cultivar Olea europaea L cv Arbequina. As azeitonas foram colocadas em cintas transportadoras que cruzavam por uma cortina de ar para a retirada das folhas que estavam junto aos frutos. Em seguida, os frutos foram selecionados por qualidade, lavados em água corrente e posteriormente submetidos a moagem. A moagem consistia na trituração dos frutos (sem a retirada prévia dos caroços) até formar uma massa oleosa, cuja consistência era controlada pela adição de água, quando necessário. A extração do azeite de oliva extravirgem (separação da fase sólida e líquida) foi realizada através do sistema contínuo por centrifugação em planta de duas fases. Nesse sistema, a massa oleosa de azeitonas foi diluída com a água de vegetação (água reciclada da lavagem dos frutos). Posteriormente, a massa seguia para uma centrífuga horizontal, na qual a parte sólida era separada da mistura oleosa. Após, a massa líquida oleosa passava por uma centrífuga vertical, na qual separava o azeite de oliva extravirgem da água de vegetação. Por outro lado, a massa sólida, formada de polpa, caroço (noz), pele e água, denominada de torta de oliva, consistia no principal coproduto da extração do azeite de oliva extravirgem.

Para caracterizar bromatologicamente a torta de oliva em diferentes períodos após sua obtenção na indústria ( 0 e 48 horas), com a finalidade de avaliar a preservação das suas características originais até 48 horas 
de estocagem, e sua consequente viabilidade para a ensilagem, utilizou-se seis recipientes plásticos hermeticamente fechados, com capacidade de $250 \mathrm{Kg}$, em cada um dos diferentes períodos após sua obtenção na indústria (0 e 48 horas).

Nos dois tempos de estocagem (0 e 48 horas) da torta de oliva foram determinados os teores de matéria seca (MS), matéria orgânica (MO), matéria mineral (MM), extrato etéreo (EE) e proteína bruta (PB), segundo AOAC (1996, métodos 967.03, 942.05, 954.05 e 920.39 respectivamente), fibra insolúvel em detergente neutro corrigida para cinzas (FDNc), fibra insolúvel em detergente ácido corrigida para cinzas (FDAc), nitrogênio insolúvel em detergente neutro (NIDN) e nitrogênio insolúvel em detergente neutro (NIDN), com adição de $\alpha$-amilase termoestável mas sem uso de sulfito (LICITRA et al., 1996). A lignina em detergente ácido (LDA) foi realizada segundo VAN SOEST et al. (1991). Os carboidratos não fibrosos (CNF) e os carboidratos solúveis (CHOS) foram determinados segundo metodologia proposta por HALL (2003). Os nutrientes digestíveis totais (NDT) foram expressos em nível de mantença pelo método proposto por WEISS et al. (1992).

Além disso, nos dois tempos de armazenamento (0 e 48 horas) da torta de oliva foram conduzidos ensaios de degradabilidade "in situ". As amostras foram analisadas em quatro repetições, sendo previamente moídas a $2 \mathrm{~mm}$ e colocadas em sacos de poliéster com tamanho de $5 \times 5 \mathrm{~cm}$ e porosidade de $50 \mu \mathrm{m}$, os quais foram selados e incubados em 4 vacas da raça Jersey, com cânulas permanentes no rúmen e adaptadas previamente ao consumo de torta de oliva como parte da dieta total. Conforme metodologia de GOERING \& VAN SOEST (1970), após 48 horas de incubação "in situ", foi determinada a digestibilidade verdadeira da matéria seca (DIVMS 30 e DIVMS 48 horas) e da FDN (DIVFDN 30 e DIVFDN 48 horas).

Ademais, foi testado o efeito de um inoculante comercial (Lactobacillus buchneri: > 7,50 x $10^{10} \mathrm{cfu} / \mathrm{g}$; Pediococcus acidilactici: > 5,00 x 1010 cfu*/g; e enzimas celulase/hemicelulase: > 20000 RÜ/g) e uma fonte de carboidrato não fibroso (farelo de trigo) no decréscimo do pH da silagem de torta de oliva.

Para tanto foram utilizados micros silos experimentais confeccionados a partir de recipientes plásticos de $224 \mathrm{~mm}$ de diâmetro e $285 \mathrm{~mm}$ de comprimento. Para tal avaliação, foram preparadas cinco repetições dos micros silos contendo torta de oliva sem inoculante comercial (tratamento 1); torta de oliva com inoculante comercial (tratamento 2); torta de oliva com inoculante comercial e 15\% de farelo de trigo (tratamento 3); e torta de oliva com inoculante comercial e $30 \%$ de farelo de trigo (tratamento 4 ). 0 material foi compactado, sendo as extremidades dos micros silos vedados com tampa hermética, equipadas com "airlock", para permitir a saída da pressão interna (devido ao $\mathrm{CO}_{2}$ formado durante a fermentação anaeróbica).

Os micros silos foram mantidos na posição vertical até a data de abertura, que ocorreu com 60 dias após a confecção. No momento da abertura, para avaliar o processo de ensilagem, foi determinado o pH, conforme metodologia de Playne \& McDonald (1966).

Os resultados foram analisados em delineamento inteiramente casualizado (DIC), utilizando o procedimento General Linear Models (PROC GLM).

As medidas foram estimadas com o comando LSMEANS (Least Squares Means) e comparadas pelo teste de Tukey ao nível de $5 \%$ de significância.

As análises estatísticas foram executadas no aplicativo SAS ${ }^{\circledR}$ System for Windows ${ }^{\mathrm{TM}}$ versão 9.0. 


\section{RESULTADOS E DISCUSSÃO}

Conforme Tabela 1 não houve diferença $(p>0,05)$ de MS, MO, MM e EE entre os diferentes tempos de estocagem ( 0 e 48 horas) da torta de oliva.

Os teores de MS, MO e MM observados neste coproduto assemelham-se as quantidades encontradas em pré-ensilado de milho (VELHO et al., 2007), porém são superiores em MS aos resultados obtidos para silagem de sorgo (SILVA et al., 2005). 0 conteúdo de MS da torta de oliva está dentro dos parâmetros considerados adequados para um bom padrão fermentativo e consequente armazenagem do material ensilado (FERREIRA, 2001).

0 conteúdo médio de EE (18,96\% na MS) apresentado na Tabela 1 demonstra que este coproduto pode representar importante alternativa alimentar para o aumento da densidade energética na dieta de ruminantes. No entanto, o principal entrave para utilização de coprodutos com elevados valores de EE, é a sua conservação a nível de produtor e o estabelecimento dos níveis ideais de inclusão na dieta.

Não houve diferença $(p>0,05)$ entre os constituintes da parede celular da torta de oliva nos diferentes tempos de estocagem (0 e 48 horas) (Tabela 2).

0 valor médio de FDN (53,58\% na MS) deste resíduo industrial (Tabela 2) estão dentro da amplitude de variação de pré-ensilados de silagem de milho (cerca de 51\%) e silagem de sorgo (cerca de 57\%) (VELHO et al., 2007; MIZUBUTI et al., 2002) e são levemente superior ao conteúdo encontrado para silagem de girassol (cerca de 48\%) (MIZUBUTI et al., 2002). No entanto, a concentração média de lignina (15,96\% na MS) da torta de oliva é bastante elevada, o que pode ser considerado como fator negativo do ponto de vista nutricional, visto que essa fração da parede celular é indigestível (OLIVEIRA et al., 2011).

Os teores dos compostos nitrogenados da torta de oliva não alteraram $(P>0,05)$ com os diferentes tempos de estocagem (0 e 48 horas) (Tabela 3). 0 teor médio de PB (8,38\% na MS) deste coproduto é semelhante aos valores do pré-ensilado de silagem de milho reportados na literatura (cerca de 7,5\%) (VELHO et al., 2006; VELHO et al., 2007). No entanto, os constituintes nitrogenados ligados à parede celular (NIDN = 54,42\% na MS e NIDA = $32,29 \%$ na MS) são ligeiramente superiores aos valores encontrados por estes mesmos autores (NIDN $=24,48 \%$ na MS; NIDA = 9,10\% na MS), o que evidencia menor qualidade da PB da torta de oliva frente aos pré-ensilados de silagem de milho.

Não houve diferença significativa $(p>0,05)$ de NDT, DIVMS e DIVFDN entre os tempos de estocagem $(0$ e 48 horas) da torta de oliva (Tabela 4). 0 valor médio estimado de NDT $(69,85 \%)$ encontrado nesse estudo foi semelhante aos evidenciados por VELHO et al. (2007) para pré-ensilado de silagem de milho (71,2\%) e superiores aos relatados por OLIVEIRA et al. (2011) para silagem de sorgo forrageiro (49,4\%) e girassol (60,2\%).

Por outro lado, a DIVMS 30 (50,57\%) e DIVMS 48 (51,51\%) da torta de oliva são inferiores aos valores reportados de silagem de milho (67,95\%) e sorgo (60,85\%), após 28 dias de ensilagem (SILVA et al., 2005). Além disso, os valores de DIVFDN 30 (20,27\%) e DIVFDN 48 (21,15\%) deste coproduto mostraram-se inferiores aos evidenciados para silagem de milho (46,23\%) (OLIVEIRA et al., 2011). Isto, segundo OBA \& ALLEN (2000), pode reduzir o consumo de MS e consequentemente o desempenho dos animais. Nesse sentido, evidencia-se a necessidade de estudos para determinar os melhores níveis de inclusão da torta de oliva, com o intuito de minimizar perdas de desempenho animal. 
Os valores de CNF da torta de oliva não diferiram ( $p>0,05)$ entre os tempos de estocagem ( 0 e 48 horas), no entanto os CHOS diminuíram $(p<0,05)$ com 48 horas de armazenamento (Tabela 5). Dessa maneira, este material poderá desenvolver fermentação alcoólica por leveduras após sua ensilagem, o que prejudicaria o valor nutritivo deste resíduo industrial.

Como as variáveis de composição bromatológica e digestibilidade não diferiram $(p>0,05)$ nos tempos de estocagem ( 0 e 48 horas) da torta de oliva, exceto quanto ao teor de CHOS, que diminuiu $(p<0,05)$ com 48 horas de armazenamento, para auxiliar na logística de transporte e manejo do coproduto que será ensilado, sugere-se utilizar a torta de oliva com 48 horas de estocagem.

$\mathrm{Na}$ avaliação da possibilidade de conservação da torta de oliva ensilada, com a utilização de inoculante comercial e farelo de trigo (Tabela 6), observou-se os menores valores de $\mathrm{pH}(\mathrm{p}<0,05)$ no tratamento com inoculante e $30 \%$ de farelo de trigo. 0 pH médio de 4,13, evidenciado neste tratamento, está dentro da faixa considerada ideal (3,6 a 4,2) para promover uma eficiente conservação da massa ensilada (McDonald et al., 1991), além de estar próximo aos valores encontrados em silagens de milho por Contreras-Govea et al. (2009) $(\mathrm{pH}=3,9)$ e Nishida et al. (2007) $(\mathrm{pH}=3,7)$.

\section{CONCLUSÃO}

Com os resultados deste estudo, para auxiliar na logística de transporte e manejo da torta de oliva à nível de propriedade rural, pode-se afirmar que é possível estocar este material por 48 horas após sua obtenção na indústria. Além disso, evidencia-se efeito positivo no processo fermentativo da ensilagem deste resíduo industrial, com a adição de inoculante comercial Lactobacillus buchneri: > 7,50 x $10^{10} \mathrm{cfu} / \mathrm{g}$; Pediococcus acidilactici: > $5,00 \times 10^{10} \mathrm{cfu}$ */g; e enzimas celulase/hemicelulase: > $20000 \mathrm{RÜ/g}$ ) e 30\% de farelo de trigo, tornando-se uma alternativa interessante de conservação deste coproduto. Ressalta-se ainda, os elevados valores de EE (18,96\% na MS) encontrados nas tortas de oliva, tornando-se necessário a realização de ensaios para a elucidação das consequências dos níveis de inclusão em dietas de ruminantes.

\section{AGRADECIMENTOS}

À Universidade de Santa Cruz do Sul, pelo apoio e auxílio financeiro prestados através do Programa UNISC de Bolsas de Iniciação Científica (PUIC).

\section{REFERÊNCIAS}

ASSOCIATION OF OFFICIAL ANALYTICAL CHEMISTS (AOAC), 1996. Official Methods of Analysis, 16th ed. AOAC, Washington, DC, USA.

CONTRERAS-GOVEA, F.E.; MUCK, R.E.; ARMSTRONG, K.L.; ALBRECHT, K.A. Nutritive value of corn silage in mixture with climbing beans. Animal Feed Science and Technology, v.150, p.1-8, 2009. 
COUTINHO, E. F.; RIBEIRO, F. C.; CAPPELLARO, T. H.; ARAÚJO, F.A. Mercados e comercialização. In: Coutinho, Ribeiro and Cappellaro (Org.). Cultivo de oliveira (Olea europaea L.). Pelotas: Embrapa Clima Temperado, 2009, 102-115.

FERREIRA, J.J. Características qualitativas e produtivas da planta de milho e sorgo. In: CRUZ, J.C., et al. (Eds). Produção e utilização de silagem de milho e sorgo. Sete Lagoas: EMBRAPA, 2001. p.383-404.

GOERING, H. K.; VAN SOEST, P. J. Forage fiber analysis: apparatus reagents, procedures and some applications. Agriculture Handbook, 379p. Washington D. C., 1970.

HALL, M. B. Challenges with nonfiber carbohydrate methods. Journal of animal science, v. 81, n. 12, p. 3226-3232, 2003.

LICITRA, G.; HERNANDEZ, T.M.; VAN SOEST, P.J. Standardization of procedures for nitrogen fractionation of ruminant feeds. Animal Feed Science and Technology, v.57, p.347-358, 1996.

McDONALD, P.; HENDERSON, A.R.; HERON, S.J.E. The biochemistry of silage. s.I.: Scholium International, 1991. $155 p$.

MIZUBUTI, I.Y.; RIBEIRO, E.L.A.; ROCHA, M.A.; SILVA, L.D.F.; PINTO, A.P.; FERNANDES, W.C.; ROLIM, M. A. Consumo e Digestibilidade Aparente das Silagens de Milho (Zea mays L.), Sorgo (Sorghum bicolor (L.) Moench) e Girassol (Helianthus annuus L.). Revista Brasileira de Zootecnia, v.31, n.1, p.267-272, 2002.

NISHIDA, T.; ERUDEN, B.; HOSODA, K. T.; MATSUYAMA, H.; XU, C.; SHIOYA, S. Digestibility, methane production and chewing activity of steers fed whole crop round bale corn silage preserved at three maturities. Animal Feed Science and Technology, v.135, p.42-51, 2007.

OBA, M.; ALLEN, M. S. Effects of brown midrib 3 mutation in corn silage productivity of dairy cows fed two connnetrations of dietary neutral detergent fiber: 1 . Feeding behavior and nutrient utilization. Journal of Dairy Science, n.6, v.83, p.1333-1341, 2000.

OLIVEIRA, A.S.; DETMANN, E.; SOUZA, J.M.C.; PINA, D.S.; SOUZA, S.M.; COSTA, M.G. Meta-análise do impacto da fibra em detergente neutro sobre o consumo, a digestibilidade e o desempenho de vacas leiteiras em lactação. Revista Brasileira de Zootecnia, v.40, n.7, p.1587-1595, 2011.

PLAYNE, M.J., McDONALD, P. The buffering constituents of herbage and silage. Journal of the Science of Food and Agriculture, v.17, p.264-8, 1966.

STATISTICAL ANALYSIS SYSTEM - SAS. The SAS system for windows. v. 9.0 Cary: SAS Institute Inc., 2002.

SILVA, A.V.; PEREIRA, O.G.; GARCIA, R.; VALADARES FILHO, S.C.; CECON, P. R.; FERREIRA, C.L.L.F. Composição Bromatológica e Digestibilidade in Vitro da Matéria Seca de Silagens de Milho e Sorgo Tratadas com Inoculantes Microbianos. Revista Brasileira de Zootecnia, v.34, n.6, p.1881-1890, 2005.

VAN SOEST, P. J.; ROBERTSON, J. B.; LEWIS, B. A. Methods for dietary fiber, neutral detergent fiber, and non starch polysaccharides in relation to animal nutrition. Journal of Dairy Science, v.74, n. 10, p. 3583- 3597, 1991.

VARGAS-BELLO-PÉREZ, E.; VERA, R. R.; AGUILAR, C.; LIRA, R.; PEÑA, I.; FERNÁNDEZ, J. Feeding olive cake to ewes improves fatty acid profile of milk and cheese. Animal Feed Science and Technology, v. 184, n. 1, p. 94-99, 2013.

VELHO, J.P.; MÜHLBACH, P.R.F.; GENRO, T.C.M.; VELHO, I.M.P.H.; NÖRNBERG, J.L.; ORQIS, M.G.; KESSLER, J.D. Composição bromatológica de silagens de milho produzidas com diferentes densidades de compactação. Revista Brasileira de Zootecnia, v.36, n.5, p.1532-1538, 2007.

VELHO, J.P.; MÜHLBACH, P.R.F.; GENRO, T.C.M.; VELHO, I.M.P.H.; NÖRNBERG, J.L.; ORQIS, M.G.; KESSLER, J.D. Alterações bromatológicas nas frações dos carboidratos de silagens de milho "safrinha" sob diferentes tempos de exposição ao ar antes da ensilagem. Revista Brasileira de Zootecnia, v.35, n.4, p.1621-1628, 2006. (Supl.). 
WEINBERG, Z. G.; CHEN, Y.; WEINBERG, P. Ensiling olive cake with and without molasses for ruminant feeding. Bioresource technology, v. 99, n. 6, p. 1526-1529, 2008.

WEISS, W.P.; CONRAD, H.R.; ST. PIERRE, N.R. A theoretically based model for predicting total digestible nutrient values of forages and concentrates. Animal Feed Science and Technology, 39, p.95-110, 1992.

Tabela 1 - Teores médios de matéria seca (MS), matéria orgânica (MO), matéria mineral (MM) e extrato etéreo (EE) da torta de oliva, com o erro padrão da média (entre parênteses), nos diferentes tempos de estocagem (0 e 48 horas) após sua obtenção na indústria.

\begin{tabular}{lccc}
\hline \multirow{2}{*}{ Variável } & \multicolumn{2}{c}{ Tempos de estocagem } & \multirow{2}{*}{ Valor de $p^{*}$} \\
\cline { 2 - 3 } & 0 horas & 48 horas & 0,06 \\
MS (\% PI) & $29,83(0,02)$ & $30,41(0,02)$ & 0,92 \\
MO (\% MS) & $96,73(0,02)$ & $96,74(0,02)$ & 0,99 \\
MM (\% MS) & $3,27(0,02)$ & $3,27(0,02)$ & 0,58 \\
EE (\% MS) & $18,85(0,02)$ & $19,07(0,02)$ &
\end{tabular}

* Valores de p maiores que 0,05 , não diferem pelo teste Tukey, a $5 \%$ de probabilidade.

Tabela 2 - Teores médios das frações da parede celular da torta de oliva, com o erro padrão da média (entre parênteses), nos diferentes tempos de estocagem (0 e 48 horas) após sua obtenção na indústria.

\begin{tabular}{lccc}
\hline \multirow{2}{*}{ Variável } & \multicolumn{2}{c}{ Tempos de estocagem } & \multirow{2}{*}{ Valor de $p^{*}$} \\
\cline { 2 - 3 } & \multicolumn{1}{c}{ 0 horas } & 58 horas & 0,53 \\
\hline FDNc (\% MS) & $53,84(0,04)$ & $33,33(0,04)$ & 0,15 \\
FDAc (\% MS) & $38,48(0,03)$ & $39,27(0,03)$ & 0,57 \\
LDA (\% MS) & $15,65(0,04)$ & $16,27(0,04)$ & 0,36 \\
Hemicelulose (\% MS) & $15,69(0,05)$ & $14,06(0,05)$ & 0,80 \\
Celulose (\% MS) & $22,82(0,04)$ & $22,99(0,04)$ &
\end{tabular}

* Valores de p maiores que 0,05, não diferem pelo teste Tukey, a $5 \%$ de probabilidade.

MS = matéria seca; FDNc = fibra em detergente neutro corrigido para cinzas; FDA = fibra em detergente ácido corrigido para cinzas; LDA = lignina em detergente ácido.

Tabela 3 - Teores médios dos compostos nitrogenados da torta de oliva, com o erro padrão da média (entre parênteses), nos diferentes tempos de estocagem ( 0 e 48 horas) após sua obtenção na indústria.

\begin{tabular}{lccc}
\hline \multirow{2}{*}{ Variável } & \multicolumn{2}{c}{ Tempos de estocagem } & \multirow{2}{*}{ Valor de $p^{*}$} \\
\cline { 2 - 3 } & 0 horas & 48 horas & 0,06 \\
PB (\% MS) & $8,20(0,02)$ & $8,57(0,02)$ & 0,64 \\
NIDN (\% MS) & $54,24(0,03)$ & $54,65(0,03)$ & 0,32 \\
NIDA (\% MS) & $32,07(0,04)$ & $32,51(0,04)$ &
\end{tabular}

* Valores de $\mathrm{p}$ maiores que 0,05, não diferem pelo teste Tukey, a $5 \%$ de probabilidade.

MS = matéria seca; PB = proteína bruta; NIDN = nitrogênio insolúvel em detergente neutro; NIDA = nitrogênio insolúvel em detergente ácido. 
Tabela 4 - Digestibilidades in situ da matéria seca (DIVMS) e da fibra em detergente neutro (DIVFDN) em 30 e 48 horas e estimativa dos nutrientes digestiveis totais (NDT) da torta de oliva, com o erro padrão da média (entre parênteses), nos diferentes tempos de estocagem (0 e 48 horas) após sua obtenção na indústria.

\begin{tabular}{lccc}
\hline \multirow{2}{*}{ Variável } & \multicolumn{2}{c}{ Tempos de estocagem } & \multirow{2}{*}{ Valor de $p^{*}$} \\
\cline { 2 - 3 } & 0 horas & $50,56(0,10)$ & 0,06 \\
\hline DIVMS 30 horas (\%) & $50,59(0,10)$ & $51,51(0,08)$ & 0,52 \\
DIVMS 48 horas (\%) & $51,52(0,08)$ & $20,28(0,07)$ & 0,06 \\
DIVFDN 30 horas (\%) & $20,27(0,07)$ & $21,16(0,07)$ & 0,10 \\
DIVFDN 48 horas (\%) & $21,15(0,07)$ & $69,39(0,11)$ & 0,47
\end{tabular}

* Valores de $\mathrm{p}$ maiores que 0,05 , não diferem pelo teste Tukey, a $5 \%$ de probabilidade.

Tabela 5 - Teores de carboidratos não fibrosos (CNF) e carboidratos solúveis (CHOS) da torta de oliva, com o erro padrão da média (entre parênteses), nos diferentes tempos de estocagem ( 0 e 48 horas) após sua obtenção na indústria.

\begin{tabular}{lccc}
\hline \multirow{2}{*}{ Variável } & \multicolumn{2}{c}{ Tempos de estocagem } & \multirow{2}{*}{ Valor de $\mathrm{p}^{*}$} \\
\cline { 2 - 3 } & \multicolumn{1}{c}{ 0 horas } & 48 horas & 0,74 \\
\hline CNF $(\%$ MS) & $6,50(0,01)$ & $6,23(0,01)$ & 0,01 \\
CHOS $(\%$ MS) & $4,59(0,03)$ & $2,29(0,03)$ & \\
\hline
\end{tabular}

* Valores de p maiores que 0,05, não diferem pelo teste Tukey, a $5 \%$ de probabilidade.

MS = matéria seca.

Tabela 6 - Potencial de hidrogênio $(\mathrm{pH})$ da silagem de torta de oliva, com o seu erro padrão da média, submetidas a diferentes combinações de inoculante comercial e farelo de trigo.

\begin{tabular}{lcc}
\hline \multicolumn{1}{c}{ Tratamentos } & pH & Erro padrão \\
\hline Torta de oliva sem inoculante & $4,79^{a}$ & 0,08 \\
Torta de oliva com inoculante & $4,76^{\mathrm{a}}$ & 0,08 \\
Torta de oliva com inoculante e 15\% de farelo de trigo & $4,77^{\mathrm{a}}$ & 0,08 \\
Torta de oliva com inoculante e 30\% de farelo de trigo & $4,13^{\mathrm{b}}$ & 0,08 \\
\hline
\end{tabular}

* Letras distintas na mesma coluna diferem entre si pelo teste Tukey a $5 \%$ de probabilidade. 